\title{
Perspectivas, motivaciones e intereses en la búsqueda de ancestrías genéticas en Buenos Aires, Argentina
}

\author{
Francisco di Fabio Rocca* / UBA, Conicet, UMAI, Argentina \\ Silvina Smietniansky / Conicet, UNQ \\ Sofía Spina / UBA \\ Elianna Coirini / UBA \\ Julia Gago / Conicet, Idaes-Unsam, UMAI \\ Lautaro Juárez / UBA \\ Roxana Boixados / UBA, UNQ, Conicet \\ Sergio Avena / Conicet, UBA, UMAI
}

Perspectives, Motivations and Interests in the Search

for Genetic Ancestry in Buenos Aires, Argentina

DOI 10.22380/2539472X.1157

\begin{abstract}
RESUMEN
Este artículo propone una aproximación etnográfica al estudio de las perspectivas, motivaciones e intereses de los individuos participantes en el proyecto "Ancestría genética e identidad". Basados en un corpus de entrevistas y en un marco teórico que utiliza los conceptos de genealogía y pedigrí, indagamos la significación que el dato genético adquiere en la recreación de las historias e identidades personales y familiares, así como el modo en que el test de ancestría genética se articula y entra en negociación con otras experiencias y registros de tipo oral o escrito. En el marco de las investigaciones desarrolladas en este campo, también señalamos la importancia de considerar los contextos sociales, jurídicos y políticos para comprender el impacto de estas nuevas tecnologías.
\end{abstract}

Palabras clave: genética, genealogía, pedigrí, identidad.

\begin{abstract}
This article proposes an ethnographic approach to the study of the perspectives, motivations, and interests of the individuals participating in the "Genetic Ancestry and Identity" project. Based on a corpus of interviews and using a theoretical framework with the concepts of genealogy and pedigree, we explore the significance of genetic data in the recreation of personal and family histories and identities, and the way in which the genetic ancestry test articulates and enters into negotiation with other experiences and records of oral and written order. Taking into account research in this field we also draw attention to the importance of considering social, legal and political contexts to understand the impact of these new technologies.
\end{abstract}

Keywords: genetics, genealogy, pedigree, identity.

fdifabiorocca@gmail.com / https://orcid.org/0000-0001-9749-9757 


\section{Introducción: sobre el proyecto "Ancestría genética e identidad"}

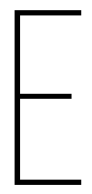

ntre los años 2014 y 2018, en el proyecto "Ancestría genética e identidad" buscamos dar una respuesta a las demandas que llegaban de manera espontánea al Equipo de Antropología Biológica ${ }^{1}$.

El proyecto refleja el pasaje de un enfoque centrado en los estudios poblacionales - principal línea de trabajo del equipo durante años-, hacia uno que indaga las perspectivas de los sujetos que voluntaria y espontáneamente deciden realizarse un test de ancestría ${ }^{2}$. Integrar el análisis genético de los participantes del proyecto en un protocolo de entrevistas sucesivas nos permitió aproximarnos a esas perspectivas y a las repercusiones que el dato genético tenía en la comprensión y la construcción de las identidades e historias familiares. En este artículo tenemos como objetivo iniciar una reflexión acerca de los intereses y motivaciones que impulsaron la realización de los test, las preguntas que el procedimiento suscitaba, el modo en que los resultados se integraban a otra clase de datos y la reacción de las familias ante los resultados. Avanzar en esta dirección, incorporando la voz de los sujetos, obligó a ampliar una mirada anterior centrada en "lo biológico".

La primera parte del artículo brinda un panorama general sobre los nuevos roles de la genética y los antecedentes en la temática. La segunda desarrolla dos conceptos útiles para entender el campo: genealogía y pedigrí. En la tercera se explicitan aspectos metodológicos del proyecto de investigación, mientras que en la cuarta se exponen y se analizan los resultados de campo. Finalmente, se plantean consideraciones preliminares de la investigación y lineamientos para continuarla.

1 El equipo desarrolla su trabajo en la Universidad de Buenos Aires y la Universidad Maimónides. El proyecto "Ancestría genética e identidad" (AG\&I) comenzó en el 2014 y actualmente se encuentra radicado como proyecto FILOCyT (FC10-097) de la Facultad de Filosofía y Letras de la Universidad de Buenos Aires.

2 Los test de ancestría genética pueden definirse como la identificación de grupos (clusters) de individuos con base en patrones de similitud y diferenciación genética (Fuentes et al. 2019), cuyos resultados buscan asociarse a regiones geográficas e historias poblacionales. En su uso más cotidiano -y comercial- se muestran como test que informan sobre el pasado, "los ancestros" de individuos y comunidades, aunque en general den cuenta de afinidades entre poblaciones presentes que solo en ciertos casos permiten hacer inferencias sobre un pasado común. 


\section{La ancestría genética: alcances, enfoques y nuevas preguntas}

En las últimas tres décadas, la genética trascendió el ámbito biomédico y la promesa de realizar "nuevos descubrimientos para salvar vidas" e ingresó en los juzgados, en el diseño y venta de genealogías, así como en la cultura popular, desafiando las maneras previas de conocerse a uno mismo (Ventura et al. 2009; Wailoo 2012). El ADN, materia prima de la genética, fue ubicado en el centro de la discusión de los más variados temas, y desde entonces los genes ocuparon el lugar que antes ocupaba la sangre como un locus simbólico central en la construcción de las relaciones de parentesco (Bestard 1998). Entendidos como unidades de información, códigos o hasta una especie de paisaje susceptible de ser mapeado y recorrido, los genes devinieron en un ícono cultural (Cunningham 2009). Pensados también como portadores de identidades, se les adjudica la capacidad de transmitir elementos corporales (similitudes físicas o enfermedades) y no corporales (como la personalidad o la inteligencia) (Álvarez 2006; Stolcke 1998). Grandes proyectos científicos (Human Genome Diversity Project, International HapMap Project, Genographic Project, entre otros), muchas veces internacionales, con financiamiento privado y estatal, se dedican a la identificación y secuenciación de variantes genéticas. Aunque mantienen considerables diferencias metodológicas, estos proyectos coinciden en muestrear poblaciones o individuos, obtener información genética y ponerla en relación con asuntos fármaco-médicos, históricos, evolutivos, buscando comprender al humano utilizando nuevas y poderosas herramientas (Reardon 2005; Wade 2017).

En referencia a los estudios de ancestría genética destinados al análisis poblacional, se suele recurrir a dos indicadores: la estimación de mezcla génica y la determinación de linajes (haplogrupos) maternos y paternos. En el primer caso se considera que la población estudiada es resultado de la mezcla de aportes de al menos dos poblaciones parentales. La población parental es una construcción metodológica, una abstracción que no debería ser reificada (aunque muchas veces lo es) y que debería tener una restricción geográfica y no una delimitación por nacionalidad o etnia, dado que las categorías sociales y de uso cotidiano conllevan otros significados y se definen con otros parámetros. La mezcla génica tiene en cuenta a todos los ancestros del individuo o población analizados, mientras que los linajes son informativos de una sola de las ramas del árbol genealógico. Los linajes maternos se establecen a través del ADN mitocondrial (ADNmt), que se hereda de madres a hijos, y los linajes paternos se establecen mediante 
el cromosoma Y, razón por la cual solo puede determinarse entre los varones. En ambos casos se tipifican mutaciones específicas que pueden indicar grupos de filiación (los linajes) que tienen una correlación geográfica vinculada con la dispersión del ser humano en los continentes ${ }^{3}$. El concepto de linaje utilizado en estudios de genética poblacional se basa en una dimensión estrictamente biológica y genética, y supone un elemento común que permite trazar unilinealmente un grupo de ascendientes. No obstante, cuando estas definiciones atraviesan ámbitos y disciplinas, otras miradas y otros sentidos aparecen ${ }^{4}$.

Los test de ancestría genética son uno de esos fenómenos científicos que han traspasado los límites del laboratorio y se encuentran cada vez más presentes en los medios de comunicación, las redes sociales o el saber popular. Un buen ejemplo de ello es la campaña The DNA Journey llevada a cabo por la empresa de viajes Momondo a partir del 2016. Su puntapié inicial consistió en un breve video en el que un grupo de individuos se definían a sí mismos en términos de nacionalidad, religión o etnia, para luego recibir de parte de dos “expertos” los resultados de su ancestría genética. Debido a que los participantes presentaban una ancestría múltiple y mezclada, las reacciones y conclusiones apuntaban de manera muy optimista a que no existiría lugar para extremismos y odios étnico-raciales si todos conocieran su $\mathrm{ADN}^{5}$. Los análisis de este tipo son llamados de genética recreativa o "test directos al consumidor" (DTC, por las siglas en inglés de directto-consumer), dado que para realizarlos basta con la voluntad y el dinero de los participantes y se caracterizan por prescindir de una finalidad médica o jurídica

Desde mediados de la década de 1990 se realizan en Argentina análisis de ancestría genética a nivel poblacional utilizando la metodología mencionada. La mayoría de los resultados se discutieron considerando la historia social y demográfica del país. Por ejemplo, en muchos ambientes todavía es parcialmente aceptada la narrativa dominante que postula a la población argentina como blanca-europea, descendiente directa de los inmigrantes ultramarinos. La presencia, en muchas ocasiones elevada y hasta mayoritaria, de componentes no europeos en el acervo génico fue utilizada para remarcar la falta de sustento de dicha narrativa. Para ampliar, véanse Avena et al. (2013), Salzano y Sans (2014) y Di Fabio Rocca et al. (2018).

4 Es importante señalar que el término linaje, que la antropología trasladó al estudio de las sociedades africanas, proviene del lenguaje medieval y que, aun dentro de las naciones europeas, implicaba sentidos dispares, que redundaban a su vez en las variables interpretaciones que los historiadores han propuesto (Goody 1986). Los test de ancestría operan con una acepción ajena a la maleabilidad de los linajes medievales, pero con aspectos que igualmente parecen solaparse con la noción sociológica y etnográfica.

$5 \quad$ El video original se viralizó rápidamente por las redes sociales y sumó más de 17 millones de vistas en sus primeros meses, lo cual es una fracción del total si consideramos las versiones dobladas, subtituladas, los otros videos de la campaña donde se explaya sobre cada participante y la distribución a través de distintas redes sociales. Un análisis pormenorizado de la campaña The DNA Journey, sus implicancias y metodología científica merecería un artículo exclusivo. Aquí nos limitamos a mencionarla para dar cuenta de su popularidad y de la cotidianeidad creciente de los datos genéticos. La campaña puede seguirse en www. momondo.com/es/letsopenourworld/dna 
definida. Las empresas que los ofrecen se han multiplicado y, para enero del 2018, entre las dos empresas más grandes (21\&Me y Ancestry.com) declaraban haber analizado a 7 millones de clientes (Mittos, Blackburn y Cristofaro 2018).

En el gran arco de las ciencias sociales, este panorama no ha pasado desapercibido, en especial, cuando se pone énfasis en las implicaciones de los análisis de ancestría en la construcción de las identidades colectivas o individuales, discurso al que apelan las propias empresas en sus estrategias de venta. Hace al menos una década comenzaron los debates sobre las limitaciones y riesgos que podía conllevar esta oferta (Bolnick et al. 2007; Frudakis 2008). Se ha discutido la capacidad de los test para modificar las identidades individuales y colectivas, para resignificar las ideas de "raza" 0 "etnicidad" (Wailoo 2012), su repercusión en la nueva biomedicina (López-Beltrán 2011) e incluso su rol en los reclamos por la restitución de restos humanos a pueblos indígenas de distintos países (Walker, Egan y Nicholas 2016), entre otros aspectos.

En Latinoamérica, un trabajo pionero de Ventura et al. (2009) analizó las autoadscripciones, las clasificaciones mediante fotografías y los resultados de mezcla génica individual de una muestra de estudiantes de Río de Janeiro. López-Beltrán (2011) analizó las repercusiones y discursos en torno a proyectos científicos estatales de medicina genómica en México, mientras que Kent y Ventura (2012) estudiaron la articulación entre investigación genética y construcción de identidades étnicas en Colombia. Estudios recientes incorporaron al análisis las voces de los participantes-donantes en proyectos genómicos, ya fuera centrándose en el rol de los rasgos fenotípicos en el momento de clasificarse (Delgado, García-Deister y López-Beltrán 2017) o en la importancia y estatuto de verdad (autoridad) otorgado a la genética en la conformación de comportamientos e identidades individuales o colectivas, dependiendo del acervo cultural, educativo y político del involucrado (Schwartz-Marín y Wade 2015).

En Argentina nuestro proyecto dialoga con otros dos que abordan las representaciones de los participantes en análisis de ancestría genética (Cabana, Mendoza y Smith 2015; García et al. 2016). En esos trabajos los análisis genéticos también provienen del ámbito académico. Los DTC privados no están prohibidos ni explícitamente reglamentados, pero no han progresado empresas locales que los realicen y enviar muestras biológicas al extranjero tiene barreras legales. Por lo tanto, aún no es un mercado desarrollado.

6 A fin de comprender la nula utilidad del concepto de raza para explicar la diversidad genética of Physical Anthropologists (Fuentes et al. 2019). 


\section{Genealogía y pedigrí: un estudio para los test de ancestría}

Durante la realización de AG\&I, las entrevistas, comunicaciones y los encuentros fueron desplegando un nuevo campo empírico que corría el foco de la línea de trabajo centrada en los estudios poblacionales. Relatos orales, fotos, documentos y memorias familiares iban cobrando protagonismo como una trama de significantes desde donde se interpretaban, daban sentido o cuestionaban los resultados de los exámenes. El saber técnico y los procedimientos de laboratorio entablaron diálogo con otros saberes y otros artefactos, y en ese proceso - característico de un estudio etnográfico que supone una aproximación a otras perspectivas que redefinen y amplían las propias (Geertz 1994; Guber 2001) — fueron surgiendo nuevas preguntas y problemáticas.

Como parte de este itinerario recurrimos a los conceptos de genealogía y pedigrí, cuyo empleo en los estudios clásicos del campo del parentesco sirvió a los especialistas para repensar la relación entre lo biológico y lo sociocultural; en esta ocasión, su uso nos permite indagar el carácter construido del vínculo entre la ancestría y la identidad, tanto en el plano colectivo (la familia) como en el individual. La selección de estos conceptos resultó de poner en diálogo los datos elaborados de las entrevistas realizadas con temas clásicos de la antropología (la identidad, el parentesco, el modelo genealógico), actualmente rediscutidos al calor de los debates suscitados por el avance de la genética y la biotecnología (Bamford y Leach 2009). Este artículo, al tiempo que se propone indagar las perspectivas de los sujetos que han participado en la realización de test genéticos, constituye una ocasión propicia para reflexionar sobre las herramientas teóricas y metodológicas que pueden aportar en la comprensión de las motivaciones, intereses e implicaciones presentes en la búsqueda de ancestrías genéticas personales. En ese sentido, el abordaje que este trabajo propone al corpus empírico que reúne las entrevistas realizadas se aproxima a un tipo de enfoque -la etnografía- que parte de reconocer la universalidad de la experiencia humana y que determina que la posibilidad de acercarnos a las perspectivas de otros sujetos descansa en el ejercicio de diálogo que nuestro saber teórico acumulado establezca con ellas. En este proceso los propios marcos analíticos del investigador -y, junto con ellos, los presupuestos y valores culturales que como miembro de una comunidad le subyacen - resultan discutidos, redefinidos y ampliados (Peirano 1995).

El hecho de que las elecciones teóricas y orientaciones analíticas propuestas aquí no se hubieran definido a priori, sino a partir de la escucha y la 
interacción con los sujetos que iban coconstruyendo nuestro campo de estudio, y de que nuevas preguntas surgieran sobre los mismos materiales (las entrevistas realizadas y desgrabadas) al responder problemáticas clásicas de la antropología, refleja el interés por acercar nuestro accionar a lo que hace un etnógrafo en el campo. También, ese ejercicio de selección y reapropiación de conceptos da cuenta de la vitalidad y actualidad que siguen teniendo autores y producciones teóricas clásicas, cuyos usos y sentidos pueden expandirse cuando los ponemos a prueba en el estudio de fenómenos novedosos para los cuales aquellas teorías no habían sido diseñadas ni pensadas; así es como, en antropología, la teoría se construye (Peirano 1995). Este es el espíritu etnográfico y reflexivo que orienta este primer análisis que presentamos.

La práctica de elaborar genealogías tiene una larga trayectoria histórica en la cultura occidental. El estudio de las representaciones gráficas - sobre todo la analogía del árbol- da cuenta de los modos de simbolización de las relaciones de parentesco características de la Europa medieval, con proyecciones durante el Renacimiento (Bouquet 1996; Klapisch 1994, 2000). Un aspecto central en este tipo de reconstrucciones es su carácter ficcional: los relatos recuperan y fijan por escrito ciertos nombres, vínculos y determinadas historias y relaciones por intereses específicos en tanto silencian otros (Duby 1990; Klapisch 1994). Las investigaciones históricas de los últimos treinta años en Europa han mostrado que las reconstrucciones de genealogías son relatos abiertos para el análisis de las representaciones familiares y de parentesco, que difieren según épocas y regiones y, sobre todo, que esconden más de lo que revelan. Cabe señalar que muchos de los problemas que los historiadores enfrentaron al trabajar sobre las genealogías ya habían sido reconocidos por la antropología clásica, a partir de la sistematización del método genealógico realizada por William Halse Rivers Rivers en 1910, posteriormente integrada al canon de técnicas de trabajo de campo antropológico. Con el fin de controlar la "veracidad" de los datos recabados en el terreno, Rivers ([1910] 1975) proponía encuestar al mayor número posible de miembros de una comunidad, procurando contrastar - sobre todo en cuanto a las categorías parentales- informaciones entre miembros de una misma familia y de otras relacionadas. Utilizado como un recurso metodológico de fácil acceso - sus informantes estaban interesados en hablar de sus respectivas genealogías-, el investigador podría reconstruir las normas que regulan la vida de una comunidad (vínculos, grados y terminologías de parentesco, e información adicional como residencia, creencia, rango social, migraciones, acceso a recursos) y, más allá de esto, penetrar en el pasado resguardado de la memoria oral.

A partir de la segunda mitad del siglo XX, el método comenzó a ser revisado y fue especialmente criticado por comportar una proyección del modelo 
occidental de parentesco en el estudio de otras sociedades ${ }^{7}$. Ya Rivers había admitido que era preciso considerar el "punto de vista nativo" para especificar categorías en las que lo social prevalece como criterio de clasificación, pero para avanzar en esa línea fue necesario esperar a la distinción operativa que propuso J. Barnes (1967) entre los conceptos de pedigrí y genealogía. El primero concierne a los relatos referidos a ancestros y conexiones entre parientes - contemporáneos o lejanos en el tiempo-, tanto orales como escritos realizados por el actor social o por un informante, siendo una "herramienta en mano de quienes operan dentro de un sistema de parentesco" (Barnes 1967, 103 citado en Boixadós 2004 , 17). Por su parte, el término genealogía se reserva para las reconstrucciones realizadas por los antropólogos, quienes, como observadores externos, podían analizar los sistemas de parentesco buscando establecer las conexiones efectivas entre las personas y sus modos de clasificación. Como veremos en el próximo apartado, las entrevistas constituyen una instancia clave en la construcción de los relatos sobre la identidad y la historia familiar de los participantes; y en ese proceso, el dato genético se integra en la elaboración, redefinición o ampliación de los pedigrís. Por otra parte, la distinción entre genealogía y pedigrí señala la importancia de atender al diálogo que se produce entre nuestras perspectivas y los procedimientos técnicos y las perspectivas de los actores.

\section{Universo de análisis y criterio muestral}

Los participantes en el proyecto originalmente se contactaron con nuestro equipo de investigación luego de conocerlo por diferentes vías: notas periodísticas, contactos académicos (asistentes a eventos científicos, estudiantes universitarios), redes personales (el famoso "boca en boca” o "bola de nieve”). Estas solicitudes dieron cuenta de la creciente difusión de la temática y a la vez fueron conformando gradualmente una muestra particular y heterogénea. No tuvimos que invitarlos ni convencerlos de participar, su propia iniciativa constituyó un atributo compartido y en ese sentido operó como un criterio que aportaba a definir

$7 \quad$ Las críticas desde la antropología (Beattie [1964] 1975; Needham 1960; Schneider [1964] 1975) a la propuesta de Ernest Gellner ([1957] 1975) de elaborar un lenguaje ideal y universal del parentesco sustentado en un esquema genealógico enfatizaban el carácter cultural y socialmente construido del parentesco, que un esquema basado en vínculos biológicos -en donde estos se equiparan a categorías sociales- no podría abordar en su totalidad. 
la composición de una muestra de casos que no estuvo influenciada por nuestros propios discursos antes de comenzar el proyecto ${ }^{8}$.

Se trata entonces de una muestra que en esta instancia de la investigación y del procesamiento de datos no tiene un alcance probabilístico ni una representatividad cuantitativa, pero que "permite descubrir relaciones entre partes del sistema global y abrir el campo a nuevos sentidos no previstos por el investigador" (Guber 2005, 76). Es decir, la exploración en ese terreno de sentidos aportó a la elaboración de nuevos interrogantes y a la formulación o ampliación de una perspectiva de análisis diferente a la que había marcado la trayectoria del equipo; pero, más aún, ese diálogo entre campo y teoría también condujo a repensar la metodología utilizada y mostró la necesidad de avanzar hacia una sistematización de los datos elaborados. En especial, advertimos la importancia de situar la toma de extractos corporales (saliva) y la entrega de resultados en un marco interpretativo más amplio que sería reconstruido a partir de una serie de entrevistas. El universo de análisis incluye un total de sesenta participantes. Los primeros veinte se acercaron en el 2014 y el 2015, tuvieron contactos más informales y en algunos casos se les pudo hacer entrevistas tiempo después de que hubieran recibido su resultado. Se suman a ellos cuarenta participantes que ingresaron entre los años 2015 y 2018, con el proyecto más estandarizado, por lo que han participado (o se encuentran en medio) de un proceso protocolizado de tres entrevistas. Estas corresponden a instancias específicas de la investigación: el inicio de la participación en el proyecto y las expectativas presentes, la entrega de los resultados ${ }^{9}$ y las repercusiones vividas tiempo después.

Aunque nos encontramos en una instancia de estandarización de los casos, cabe mencionar algunas características generales del recorte empírico. La gran mayoría de los participantes ( $90 \%$ ) viven en la ciudad de Buenos Aires; son más mujeres (62\%) que hombres, y se encuentran principalmente en el rango etario de 20-35 años (49\%), seguido por el de 36-50 años (41\%). No hemos recibido solicitudes que busquen resolver identificaciones forenses o paternidades, por lo que toda la muestra entra en la mencionada genética recreativa. A su vez,

8 Esto marca una diferencia con estudios que deben invitar participantes para conformar la muestra, prometiendo resultados o utilizando distintas estrategias de convencimiento.

9 Los análisis realizados consistieron en la determinación de linajes maternos a través de la secuenciación de la región control del ADN mitocondrial. La extracción de ADN mitocondrial a partir de la saliva, la amplificación y la purificación de la región control fueron hechas en nuestro propio laboratorio, al igual que la lectura de secuencias y asignación de linajes. La secuenciación fue tercerizada y se realizó en la Unidad de Genómica del Instituto Nacional de Tecnología Agropecuaria (INTA), en Hurlingham, provincia de Buenos Aires (para detalles técnicos y el software utilizado, véase Di Fabio Rocca et al. [2018]). No se realizaron estimaciones de mezcla génica individual por limitaciones del laboratorio. 
como se desarrolla a continuación, los participantes se acercaron sin tener una clara distinción sobre qué estudios realizaba el equipo ni qué tipo de dato podía brindar cada uno. Siguiendo a Roth y Lyon (2018), elaboramos una clasificación de las motivaciones e intereses que llevaron a los participantes a solicitar un análisis genético, partiendo de categorías surgidas de los sujetos y no establecidas de antemano. Estas categorías no son excluyentes entre sí y su explicitación por parte de los sujetos puede surgir en diversos momentos de las entrevistas. Distinguimos entonces una serie de categorías: la curiosidad que motivó a buscar datos nuevos y ampliar la información genealógica disponible; el interés de corroborar, verificar o probar algún dato, historia o idea preexistente; las ganas de develar o descubrir algo distinto a lo conocido; la posibilidad de conocer algo que pueda completar o reparar una historia que se siente fragmentada. Otros motivos que distinguimos fueron la búsqueda o la necesidad relacionadas con el ámbito laboral, profesional o académico; el interés por las novedades científicas, y la decisión de realizarse un test genético por acompañar a un familiar o amigo. Las categorías restantes corresponden al interés del equipo por estudiar los procesos de mestizaje e identidad en el país (Di Fabio Rocca et al. 2018) y distinguen motivación por conocer la información de la ancestría según la región: americana, europea, africana o del Cercano Oriente.

\section{Análisis de campo y discusión}

Diversos intereses y motivaciones llevaron a los participantes a solicitar un estudio genético, algunos más explícitos que otros y en general combinados entre sí. Los resultados de la clasificación se muestran en la tabla 1.

Tabla 1. Intereses y motivaciones de los participantes al momento de solicitar un análisis de ancestría genético

\begin{tabular}{l|c|c}
\multicolumn{1}{c|}{ Interés/motivo } & Número & Porcentaje (\%) \\
Curiosidad genealógica & 40 & 66,66 \\
\hline Corroborar/probar/verificar & 17 & 28,33 \\
\hline Develar & 7 & 11,66 \\
\hline Completar/reparar & 10 & 16,66 \\
\hline Profesional/laboral/ académico & 12 & 20 \\
\hline Ciencia & 8 & 13,33 \\
\hline
\end{tabular}




\begin{tabular}{l|c|c}
\multicolumn{1}{c|}{ Interés/motivo } & Número & Porcentaje (\%) \\
\hline Amigo/familiar & 8 & 13,33 \\
\hline Ancestría americana & 18 & 30 \\
\hline Ancestría europea & 6 & 10 \\
\hline Ancestría africana & 6 & 10 \\
\hline Ancestría del Cercano Oriente & 7 & 11,66 \\
\hline
\end{tabular}

Nota: Ios porcentajes están calculados con base en una muestra de 60 participantes.

Fuente: elaboración propia.

En una primera instancia fue frecuente la apelación a la curiosidad como justificación para contactarse con el equipo. En el transcurso de las entrevistas, algunas de las cuestiones planteadas como simple interés luego asumían un carácter más complejo y elaborado. Marcos ${ }^{10}$ dijo que quería participar "de curioso más que nada", para luego ampliar que le interesaba "ver de dónde se viene" (entrevista, 21 de mayo del 2015). Alessandra primero destacó su "espíritu investigador, la curiosidad me va a matar", y el incentivo de colaborar en una investigación, porque consideraba que los estudios genéticos habían sido importantes en nuestro país. Al continuar con el relato y armar su árbol genealógico, comentó su interés en una "verificación de esa bisabuela indígena” (entrevista, 29 de diciembre del 2015).

El interés explícito en utilizar el análisis de ADN para probar o corroborar un relato familiar, una relación con un ancestro destacado o una región específica apareció en el $28,33 \%$ de las oportunidades. El propósito de develar también surgió entre los participantes y refleja cómo, a pesar de encontrarnos en un sistema de parentesco cuya norma contempla ambas ramas, materna y paterna en un mismo plano de importancia, en la práctica los pedigrís que elaboran las personas pueden otorgar mayor visibilidad o preponderancia a alguna de las líneas de ascendencia. Julieta contó que conocía el origen de la mayor parte de su ancestría, migrantes de Europa del Este, por lo que no esperaba encontrar "sorpresas”, pero sí tenía expectativas "por parte de mi mamá... hay uno ahí perdido que dice... que es comechingón ${ }^{11}$ ”, y esperaba que eso "salga” en el análisis (entrevista, 11 de junio del 2015). Las ideas de curiosidad y sorpresa también aparecieron en el discurso de Virginia, interesada en algún dato que denotara ancestría americana para "romper un poco con toda la endogamia" de su familia, identificada con los inmigrantes alemanes del Volga (entrevista, 2 de noviembre

10 Para respetar el anonimato de los participantes se utilizan nombres ficticios.

11 Pueblo originario del centro de la Argentina. 
del 2017). En estas instancias se observa la maleabilidad de los relatos genealógicos y, más aún, el proceso mismo de construcción del pedigrí; no obstante, ese carácter ficcional opera dentro de ciertos márgenes, pues, por ejemplo, para romper o poner en cuestión los recortes genealógicos con los que se acercan los participantes - como en el caso de Virginia- es necesario que el dato genético actúe proveyendo nueva información.

Verónica nos contactó con la intención de “saber algo más” de su bisabuela Mamá Tora, una antepasada "recontranegra” muy querida y reverenciada por la parte materna de su familia. Se advierte en las entrevistas que el interés tan marcado en Mamá Tora implicó un claro subregistro de otras ramas familiares, ya que prácticamente no mencionó datos o historias de sus abuelos paternos (entrevista, 29 de abril del 2015). El análisis de ADN mitocondrial resultó adecuado para el interés de Verónica - orientado hacia su línea materna- e indicó que tenía un linaje mitocondrial africano. Si bien no dudaba de la afrodescendencia de Mamá Tora y sus familiares (conocida y probada a través de relatos y fotos), al conocer el resultado señaló que se sentía “un poquito más negra” y le daba orgullo saberlo (entrevista, 25 de agosto del 2015). Otro caso es el de María, quien en un primer momento aspiraba a conocer "algo más” sobre su ancestría e "investigar sobre el cuerpo”, sin mayores especificaciones. Pero luego, además de afirmar tener "sangre comechingona, alemana, española y criolla", en sus dichos se fue destacando la presencia de la Abuela Cruz, ancestra protagonista de una "serie de relatos que rozan lo fantástico y que es reinteresante”. La Abuela Cruz era curandera, hablaba de una forma particular y eso "se creía que venía de sus raíces” indígenas comechingonas (entrevista, 28 de mayo del 2015). Pero la ubicación de la Abuela Cruz en el árbol genealógico no resultaba clara; incluso en una entrevista María se retracta y refiere que es su "bisabuela de parte paterna” (entrevista, 7 de octubre del 2015). El término abuela parece más una etiqueta amplia que la referencia a una posición en la trama genealógica o a una categoría clasificatoria, a tal punto que para María "todavía se presentan como un mito, ni siquiera sé si es real”. En este caso el ADN mitocondrial indicó la presencia de un linaje materno europeo, pero dado que no se sabe si la Abuela Cruz se encuentra en dicha línea de ascendencia, el resultado no fue muy significativo. El carácter mítico de esta figura y el hecho de recurrir a un test de ancestría para iluminar algún aspecto de su existencia con implicaciones en la trama familiar sugieren que, en este proceso de construcción del relato genealógico, el dato genético queda del lado de la "realidad" como un "dato duro", un indicio que podría, con otro tipo de eficacia — distinto al que supone la transmisión oral—, confirmar la historia de la Abuela Cruz. 
En otros casos, se buscaba corroborar la relación con un lugar o una serie de lugares, antes que con un ancestro. Haciendo hincapié en las colonias de inmigrantes de donde venían las distintas ramas de su familia, Damián quería saber “¿qué tan italiano soy?”. Además, como una de sus ramas provenía de las zonas donde se habla el dialecto italoalbanés, también buscaba responder “¿qué tanto de turco tengo?”12 (entrevista, 21 de septiembre del 2017). Por su parte, Karen se acercó para conocer más sobre el lugar de nacimiento preciso de todos sus bisabuelos armenios. La pertenencia a la comunidad armenia dominaba su historia: apellido tradicional, colegios comunitarios y diversas prácticas culturales en las que participaba. No necesitaba confirmar su ancestría armenia sino que quería conocer un dato adicional y específico. Pero el análisis de ADNmt no ofrece tal precisión; un linaje puede tener cierta correlación continental o incluso regional, pero nunca al punto de diferenciar una ciudad de otra a 100 kilómetros. De todas formas, Karen participó en el proyecto y al completar su árbol genealógico se evidenció que, a diferencia de los otros tres abuelos nacidos en Armenia, su abuela materna había nacido en Entre Ríos y tenía ascendencia "vasco-francesa y española” (entrevista, 22 de abril del 2015). El análisis genético informó de un linaje materno nativo americano que significó una gran sorpresa para Karen; la nueva herramienta no solo no esclareció su duda inicial, sino que además le brindó un dato inesperado, sin conexión con el pedigrí que reconocía como propio. Posteriormente, al hablar de las repercusiones del análisis, notamos que el dato se había integrado de manera diferencial entre sus parientes. Ella lo asimiló con alegría y se sintió "más completa”, ya que ahora tenía "una parte armenia, otra argentina y además una originaria”. Por el contrario, su madre mantuvo intacto su propio pedigrí: ignoró el dato diciendo "que no significaba nada” y perdió todo el interés en la genética (entrevista, 28 de septiembre del 2016).

También, en el caso de Solange, arqueóloga interesada en ser analizada por una cuestión metodológica de su trabajo ${ }^{13}$, fueron diversas las reacciones frente a la aparición de un nuevo dato. Solange mencionó que tenía bastante conocimiento de su árbol genealógico, en buena medida gracias a su "abuela que era mormona, y ellos tienen un gran interés y mucho estudio en las genealogías”. Dado que por línea materna la información llegaba solo un par de generaciones atrás y se indicaba como “criollos”, sospechaba que el linaje podía ser

\footnotetext{
12 En Argentina es común el uso del gentilicio turco para referirse a una amplia gama de poblaciones y nacionalidades del Cercano Oriente y Europa del Este.

13 Los estudios de ADN en restos esqueletales son muy susceptibles a la contaminación. Todos los investigadores deben tener su información genética tipificada a fin de poder compararla con los resultados obtenidos.
} 
americano, lo que confirmó el análisis. A su abuela “no le gustó ni medio” el nuevo dato ya que le resultaba contradictorio con lo que indicaban sus apellidos de claro origen europeo. Solange, por su parte, indicó que "grabaría en el carnet de arqueóloga el origen americano [...] para mí como arqueóloga es algo que te da power en las negociaciones de las cosas y las construcciones de las identidades” (entrevista, 1. $^{\circ}$ de septiembre del 2015). Si bien no lo había buscado activamente, utilizó y resignificó su linaje americano, encontrándole un lugar coherente en su pedigrí y provechoso en su vida profesional.

Los intereses y motivaciones de los participantes resultan similares a los registrados en un proyecto de genotipificación a escala latinoamericana (Schwartz-Marín y Wade 2015); en él algunos voluntarios colombianos se interesaron en conocer su propio mestizaje o su relación con familias y personajes determinados. Entre otros testimonios, un individuo quería saber si era un "López puro" y otro buscaba probar su conexión con uno de los padres fundadores de Antioquia. En nuestro proyecto, notamos que algunos participantes (16,66\% del total) se acercaron explícitamente con la expectativa de reparación, de completar lo incompleto, como lo definió Nelson (2012) ${ }^{14}$. Una de las participantes lo explicó con la imagen de "tapar baches" existentes en su reconstrucción genealógica. Esta expectativa era pronunciada en el caso de participantes con una familia adoptiva, pero se observó también en otras situaciones.

Omar se acercó al equipo buscando información sobre su ancestría materna ya que su madre era adoptada y no tenía datos sobre su "familia biológica": “quería ver cuál era mi ancestría del lado maternal porque la de mi papá está bien establecida [...] y quería saber un poco más de la historia, a ver de dónde venía yo [...] para saber de dónde uno viene. Siempre es bueno saber de dónde uno viene” (entrevista, 22 de abril del 2016). Mientras su muestra era analizada, Omar se enteró de que su abuela biológica era cordobesa, por lo que pidió información específica de esa provincia para contextualizar mejor el dato que recibiría después. Por su parte, Laura, siendo adoptada, también recurrió a la genética para conocer sobre su “familia biológica”: “mi mamá como que mucho no me contó y dije 'buenísimo, estaría bueno saber', porque no sé nada y, obviamente, como soy bióloga soy recuriosa” (entrevista, 23 de noviembre del 2015). Durante las entrevistas se repitió la expresión de “no saber nada” y, dada su trayectoria profesional, Laura se sentía cercana a la información genética.

\footnotetext{
14 El concepto de reparación se encuentra asociado en distintos ámbitos y momentos a la información y las tecnologías genéticas (véanse Fonseca 2015; Nelson 2012; Smith 2015). Es intención del equipo profundizar esta temática en futuros trabajos.
} 
En la búsqueda de “completar lo incompleto”, el análisis genético interactúa con otras herramientas y actividades. El armado de series de pedigrí con base en testimonios de familiares es uno de los más comunes; muchos participantes tenían un árbol genealógico armado previamente a partir de relatos familiares, documentos y bases de datos en internet. En esta lógica se inscribe la actitud de la madre de Julieta, quien refería que "la que se entusiasmó más es mi vieja. Yo le decía: 'mami, no hace falta'. Empezó a meter en cajones, sacando... ¿viste? Partidas de nacimiento amarillentas [...]. Ella sí estaba mucho más entusiasmada [que el padre]" (entrevista, 11 de junio del 2015).

Otros testimonios dan cuenta del uso de documentos, especialmente del valor y el peso de las imágenes: “yo empecé a ver fotos y ahí me empezó a cerrar todo" (madre de Verónica, refiriéndose a sus parientes “bien morochas”) (entrevista, 29 de abril del 2015). Al hablar de sus abuelos y dando cuenta de los inicios de su interés genealógico, Santiago dijo: “no los conocí personalmente, tal vez eso incentivó más el vacío que tenía de la información, me hacía buscar y revisar fotos y quería saber quién era este, quién era el otro, investigar; después fui al registro civil de Río Cuarto, siempre fui muy necesitado de esa información (entrevista, 23 de julio del 2015). Mario fue el participante más longevo (92 años) y llevaba más de 45 años como “un fanático” de investigar su genealogía, utilizando un gran número de archivos y bases de datos e incluso con artículos escritos sobre su familia. Movido por la curiosidad, se quejó de familiares y archivistas europeos que aportaban pocos datos, quizá por desinterés o porque "en algunos casos tienen temor de que uno vaya a pedir herencias... y esas cosas ¿no?” (entrevista telefónica, 24 de enero del 2017).

En Argentina, desde hace treinta años aproximadamente, la genética ocupa un lugar clave en los procesos de restitución de los restos de personas desaparecidas a sus familias y en la búsqueda de los niños apropiados durante la última dictadura militar, lo cual les otorga un valor diferencial a las perspectivas locales sobre el tema que indaga este artículo. Las experiencias pueden entrecruzarse y potenciarse. Toda la familia de Verónica, quien se acercó intrigada por su ancestría afro, había dado muestras de saliva al Banco Nacional de Datos Genéticos con la esperanza de identificar a una tía detenida-desaparecida. Por su parte, Raquel es una docente universitaria que conocía los trabajos de nuestro equipo y quiso participar en el proyecto. Al preguntarle por qué estaba interesada, nos contó que "siempre me fascinó todo lo que es el ADN" y que no era su primera experiencia: en la década de 1980 se había realizado uno de los primeros test de paternidad del país para que el poder judicial reconociera la identidad de su hijo, cuyo padre era un detenido-desaparecido (entrevista, 5 de diciembre del 2016). 
Las experiencias también se entrecruzaron con otras actividades que los participantes realizan como formas de "poder conocerse por distintos medios”, según explicaba Luciana (entrevista, 4 de noviembre del 2015). En muchos casos, los viajes a lugares de residencia de abuelos se relatan como experiencias de extrañamiento: una forma de alejarse para encontrarse. También, el estudio de idiomas de los ancestros se describe como una forma de "entrar a otra cosmovisión, a otro modo de pensar”, y desde allí conocer algo más de los propios orígenes. Esto señala María, actriz, coreógrafa y directora de teatro, que veía el análisis como un componente de una búsqueda mayor que plasmaría en su próxima obra ${ }^{15}$. En ese proceso fue muy importante la práctica de yoga kundalini que "está ligado a la tierra y a todo el sistema nervioso"; la decisión de realizar el test de ancestría llegó luego de una “experiencia en particular”, la convivencia de ocho días con un "maestro que mezcla con chamanismo” y que define como la realización de "un viaje [...]. Impresionante” (entrevista, 7 de octubre del 2015). Así mismo, disciplinas y actividades asociadas a la meditación, el orientalismo e incluso la new age o distintos tipos de misticismo han aparecido explícitamente en las búsquedas. Al preguntarle por su interés en el test, Luciana habla de la “curiosidad por el origen” y menciona a una tía con la que practicaba yoga y que había comenzado una "terapia de constelación familiar” como parte de su búsqueda personal. En el mismo relato hace referencia a "la adivinicación [...] estuve en Salta un tiempo y estuve con una señora que tiraba las hojas de coca”, a la que le preguntó cuestiones sobre su abuela. En una entrevista muy emotiva, Andrea contó que, paralelamente al análisis genético, realizaba una terapia de generaciones pasadas, movilizada por la necesidad de entender

cómo me desenvuelvo, o sea los problemas, los conflictos que tengo, a los que vuelvo todo el tiempo en esos patrones que repito y que entiendo que los repitió mi madre y que mi abuela y mi bisabuela y, nada, me interesaría bastante saber cómo, en qué contexto, o sea, qué es lo que vivieron ellas, obviamente ustedes por ahí no me pueden dar ese dato pero es algo que me orienta. (Entrevista, 4 de octubre del 2017)

\footnotetext{
15 Algunos miembros del equipo asistieron al estreno de la obra, que podría definirse como teatro de vanguardia. En una escena, las protagonistas escupen reiteradamente el escenario para representar la toma de muestra en el laboratorio.
} 


\section{Consideraciones finales}

La distinción entre genealogía y pedigrí se vislumbra como una herramienta potente para abordar los relatos que, tejidos a través de múltiples materiales, ofrecen las personas interesadas en hacerse el test de ancestría. En los casos examinados, las fotos, los documentos familiares, las historias de los ancestros y las memorias que se heredan de generación en generación responden a la lógica nativa del pedigrí, que a su vez incorpora un nuevo dato, el genético, con la intención de generar o evidenciar lazos; en ese ejercicio que hace primar unas historias y lazos familiares sobre otros, se devela el carácter ficcional propio del discurso genealógico.

Estas nociones generales podrían estar en la base de las reconstrucciones genealógicas en las que se procura localizar antepasados, precisar su origen o procedencia o identificar parientes dispersos más o menos lejanos mediante búsquedas de información documental; así como en otros contextos históricos ${ }^{16}$ los actores sociales utilizaron las genealogías de acuerdo con sus intereses para describirse como "herederos de". Las búsquedas en el laboratorio también son caminos que nuestros interlocutores emprenden para manipular, modificar 0 performar su historia buscando, en muchos casos, un "valor agregado" a determinadas prácticas. Las entrevistas que acompañan al test aportan datos a partir de los cuales se puede construir un registro de expectativas, proyecciones, representaciones familiares e identitarias y relaciones de ascendencia que marcan, al igual que un pedigrí, estacas de una memoria colectiva más amplia.

Ahora bien, ¿se impone el dato genético sobre los otros? La respuesta no es concluyente. El discurso genético se promociona desde las nociones de verdad y objetividad —el "dato duro"- ligadas a la biología, una ciencia mucho más exacta (al menos en los estereotipos populares) que las ciencias sociales. Sin embargo, se presentaron casos en los cuales el dato genético se deja a un lado y no obliga a repensar pedigrís ni identificaciones. Las familiares de Karen y Solange ignoraron el dato al no estar de acuerdo con lo que este informaba, con la particularidad de que ellas no habían buscado activamente la información genética. Julieta buscaba una confirmación de ancestros comechingones, que no necesariamente estarían en su línea materna; la determinación de un linaje europeo no cambió sus perspectivas ni esperanzas en la búsqueda. Sin ser dejado de lado,

16 Véanse, por ejemplo, los trabajos realizados sobre el Noroeste argentino (NOA) colonial (Boixados 2004, 2005). [N. de los autores]

El (NOA) es una región histórico-geográfica formada por las provincias de Salta, Jujuy, Tucumán, Catamarca, La Rioja y Santiago del Estero. [N. del e.] 
en otros casos al dato genético se lo consideró “complementario” y “en igualdad de condiciones” frente a, por ejemplo, la terapia de generaciones pasadas, sin encontrar contradicción entre los postulados de cada marco interpretativo. La confrontación de los datos provistos por fuentes nítidamente diferenciadas - la memoria social culturalmente modelada y la tecnología genética - abre una brecha fructífera para indagar las transformaciones que estos procedimientos articulados provocan en las personas y en su entorno familiar. Delgado, GarcíaDeister y López-Beltrán (2017) encontraron que participantes en un estudio en México resignificaban el "concepto técnico de ancestría genética a partir de evidencias orales, visuales, privadas y compartidas que son interpretadas mediante lo que llamamos fenómenos de la herencia” (333, énfasis en el original); dichos fenómenos son los utilizados para "negociar la pertenencia” a un grupo u otro. Observan que, "a partir de los signos y símbolos del cuerpo, los participantes pueden establecer narrativas que concuerdan con otros fenómenos de la herencia como las historias familiares, pero también pueden encontrar puntos de discordia” (319). Por su parte, Schwartz-Marín y Wade (2015) muestran que las apropiaciones de datos genéticos (incluidas las actitudes de negación e indiferencia) variaban entre participantes según su trayectoria académica, política o región de origen. Profesionales en ciencias biológicas o forenses dieron en general un mayor peso de verdad a la genética que los estudiantes de ciencias sociales; activistas políticos (tanto en grupos afrocolombianos como entre supremacistas blancos) dijeron darles un mayor peso a sus ideas y prácticas que a los resultados eventuales de un test genético. La relación entre identidades sociales y datos de ancestría es un asunto “ambivalente, multivalente y ambiguo” y el dato genético puede entenderse como "una maleable red de elementos disponibles para su uso estratégico” (Schwartz-Marín y Wade 2015, 903; traducción propia).

Las entrevistas también muestran que, a pesar del mentado carácter bilateral del parentesco occidental, las líneas filiatorias no necesariamente reproducen una relación de simetría o equivalencia. En algunos casos, como vimos, se recurre al test genético para reponer información de la línea que ha quedado más opacada. La sistematización de todos los casos que integran la muestra de cara a este problema podría arrojar luces sobre la existencia o no de una tendencia a jerarquizar una línea sobre otra.

Como dijimos, los interesados que se contactan con nuestro equipo lo hacen a título personal y en términos de genética recreativa. ¿Qué pasaría si estas técnicas se utilizaran en ámbitos judiciales para, por ejemplo, tratar de confirmar una pertenencia étnica? ¿Y si esa pertenencia estuviera asociada a políticas concretas como un reclamo territorial? También importa interrogarse sobre las 
implicaciones de relacionar las ancestrías geográficas con predisposiciones al desarrollo de determinadas enfermedades o características hereditarias ${ }^{17}$. Como indican las discusiones acerca de las cuotas raciales de ingreso a las universidades en Brasil (Ventura et al. 2009), la presencia de datos genéticos en problemáticas cotidianas y las múltiples vidas de los objetos científicos son comunes, o al menos ya se han atravesado en otros países de la región, pero todavía tienen poco desarrollo en Argentina ${ }^{18}$ (Kent et al. 2015). Para una mejor comprensión del impacto de los datos genómicos es necesario ampliar los estudios a otros ámbitos públicos, más allá de grupos específicos interesados en su ancestría o participantes en estudios médicos (Schwartz-Marín y Wade 2015).

El último eje a considerar es la influencia de esta tecnología novedosa más allá de sus resultados directos. La elaboración genealógica, que para los participantes opera como una suerte de "herramienta en mano", nos permite, siguiendo a Rivers ([1910] 1975), "ver más allá” de lo que a priori parece reducirse al conocimiento de la ancestría genética. Las motivaciones que tienen los participantes y las repercusiones registradas después de la entrega de los resultados despliegan todo un repertorio de saberes subyacentes, así como de nuevas preguntas, reflexiones y redescubrimientos que trascienden largamente el interés por la tipificación genética. La posibilidad de participar en el proyecto muchas veces inició, reforzó o estimuló búsquedas por otros medios, mostrando la importancia que la historia familiar y la figura de los ancestros mantienen todavía en la construcción de la identidad individual. Se vuelven a tocar temas poco hablados, se reactivan recuerdos dejados en un segundo plano e incluso se restablecen contactos con familiares distanciados, una suerte de fuerza agregadora que aproxima a las personas (Fonseca 2015). En los casos estudiados, esto suele suceder antes de la primera entrevista. ¿La eficacia del test en términos de construcción de pedigrís reside en los resultados o en el mismo proceso que involucra una secuencia de entrevistas, extracción de muestras y análisis de laboratorio que proveen el marco para repensar la propia historia? Explorar el valor que los participantes otorgan a los resultados e indagar qué aspectos específicos del procedimiento del test impactan en la elaboración o reelaboración de los pedigrís es un campo de investigación que amerita profundizarse en futuros trabajos.

¿Qué pasará cuando los análisis sean cada vez más comunes y más informativos? El avance de estas experiencias tecnológicas sobre el campo de las

17 Tal como lo muestra la investigación sobre albinismo en la comunidad de Aicuña en La Rioja, Argentina (Castilla y Castilla 2017). 
representaciones parentales permitirá poner activamente en relación el pedigrí y la genealogía. En la medida en que las nuevas tecnologías genéticas aporten información con respecto a conexiones biológicas en el pasado, asistiremos a deconstrucciones y resignificaciones de los vínculos del parentesco de los informantes. Nuevos espacios de discusión se vislumbran acerca de los roles que asumen la biología y la cultura, tanto en la construcción de las representaciones del parentesco como en la redefinición de las identidades basadas en esa clave.

\section{Agradecimientos}

El proyecto se llevó a cabo gracias a Subsidios Intramuros de la Fundación Felipe Fiorellino y PICT 2014-3012. Agradecemos a todas las personas que se acercaron y compartieron sus historias.

\section{Referencias}

Álvarez Plaza, Consuelo. 2006. "Múltiples maternidades y la insoportable levedad de la paternidad en reproducción humana asistida”. Revista de Antropología Social 15: 411-455. https://revistas.ucm.es/index.php/RASO/article/view/RASO0606110411A

Avena Sergio, Francisco di Fabio Rocca, María Bárbara Postillone y Cristina Dejean. 2013. “Existió el crisol de razas en Argentina? Una respuesta desde la antropogenética”. En La complejidad después de Babel. Diásporas, culturas y transnacionalización, compilado por Beatriz Gurevich, 279-312. Buenos Aires: Lumiere.

Bamford, Sandra y James Leach, eds. 2009. Kinship and beyond. The Genealogical Model Reconsidered. Nueva York: Berghahn Books.

Barnes, Jonathan. 1967. “Genealogies”. En The Craft of Social Anthropology, editado por Arnold L. Epstein, 101-127. Londres: Social Sciencies Paperbacks.

Beattie, John H. (1964) 1975. "Parentesco y antropología social”. En Dumont (1964) 1975, 155-161.

Bestard Camps, Joan. 1998. Parentesco y modernidad. Buenos Aires: Paidós.

Boixadós, Roxana. 2004. "La genealogía como fuente y como método de análisis históricoantropológico de los procesos de creación de identidades familiares en La Rioja colonial”. Historia Indígena 8: 7-25. https://revistas.uchile.cl/index.php/RHI/article/view/40168/41731 
-. 2005. "No ha tenido hijo que más se le parezca así en la cara como en su buen proceder: una aproximación al problema del mestizaje y la bastardía en La Rioja colonial”. Memoria Americana 13: 83-115. http://antropologia.institutos.filo.uba.ar/sites/antropologia.institutos.filo.uba.ar/files/revistas/adjuntos/Memoria_Americana_13.pdf

Bolnick, Deborah, Duana Fullwiley, Troy Duster, Richard Cooper, Joan Fujimura, Jonathan Kahn, Jay Kaufman, Jonathan Marks, Ann Morning, Alondra Nelson, Pilar Ossorio, Jenny Reardon, Susan Reverby y Kimberly TallBear. 2007. "The Science and Business of Genetic Ancestry Testing”. Science 318: 399-400. https://doi.org/10.1126/scien ce. 1150098

Bouquet, Mary. 1996. "Family Trees and their Affinities: The Visual Imperative of the Genealogical Diagrama”. Journal of the Royal Anthropological Institute 2 (1): 43-66.

Cabana, Graciela, Marcela Mendoza y Lindsay Smith. 2015. "La ancestralidad genética en relación a la identidad nacional”. Documento presentado en XII Jornadas Nacionales de Antropología Biológica, 22-25 de septiembre. Corrientes, Argentina.

Castilla, Eduardo y Lucio Castilla. 2017. Aicuña. Retrato de un continente. Buenos Aires: Eudeba.

Cunningham, Hilary. 2009. "Genes, Mobilities and the Enclosures of Capital: Contesting Ancestry and its Applications in Iceland”. En Kinship and beyond. The Genealogical Model Reconsidered, editado por Sandra Bamford y James Leach, 111-138. Nueva York: Berghahn Books.

Delgado, Ángela, Vivette García-Deister y Carlos López-Beltrán. 2017. “¿De qué me ves cara?: narrativas de herencia, genética e identidad inscritas en la apariencia”. AIBR: Revista de Antropología Iberoamericana 12 (3): 313-337. http://dx.doi.org/10.11156/aibr. v12i3.68194

Di Fabio Rocca, Francisco, Sofía Spina, Elianna Coirini, Julia Gago, Jessica Patiño Rico, Cristina Dejean y Sergio Avena. 2018. "Mestizaje e identidad en Buenos Aires, Argentina. Experiencias desde la búsqueda individual de datos genéticos”. En Anales de Antropología 52 (1): 165-177. http://www.revistas.unam.mx/index.php/antropologia/article/ view/62655/59354

Duby, George. 1990. "Estruturas familiares na Idade Média occidental”. En Idade Média, Idade dos Homens. Do amor e outros ensaios, 120-128. São Paulo: Companhía das Letras.

Dumont, Louis, comp. 1964 (1975). Introducción a dos teorías de la antropología social. Barcelona: Anagrama.

Fonseca, Claudia. 2015. “Time, DNA and Documents in Family Reckonings”. Vibrant 12 (1): 75-108. http://www.vibrant.org.br/claudia-fonseca-time-dna-and-documents-in-familyreckonings/

Frudakis, Tony. 2008. “The Legitimacy of Genetic Ancestry Tests”. Science 319: 1039-1040. https://doi.org/10.1126/science.319.5866.1039b.

Fuentes, Agustín, Rebecca Rogers Ackermann, Sheela Athreya, Deborah Bolnick, Tina Lasisi, Sang'Hee Lee, Shay-Akil McLean y Robin Nelson. 2019. "AAPA Statement on Race and Racism”. American Journal of Physical Anthropology 169 (3): 400-402. https://doi. org/10.1002/ajpa.23882 
García, Angelina, Renata Oliveira Rufino, Ana Belén Bergese, Juan Francisco Agüero, Agustín Cuevas, Gabriela Díaz-Rousseau, Maia Pauro, Rodrigo Nores, Yaín GaritaOnandía, María Pía Tavella y Darío Demarchi. 2016. "El cruce entre las antropologías. Una mirada interdisciplinaria en torno a la genética de poblaciones, las memorias familiares y la construcción identitaria”. Revista del Museo de Antropología 9 (2): 105-112. https://doi.org/10.31048/1852.4826.v9.n2.13614

Geertz, Clifford. 1994. Conocimiento local. Ensayos sobre la interpretación de las culturas. Barcelona: Paidós.

Gellner, Ernest. (1964) 1975. “Lenguaje ideal y estructura de parentesco”. En Dumont (1964) 1975, 145-154.

Goody, Jack. 1986. La evolución de la familia y el matrimonio en Europa. Barcelona: Herder.

Guber, Rosana. 2001. La etnografía. Método, campo y reflexividad. Buenos Aires: Norma.

-. 2005. El salvaje metropolitano. Reconstrucción del conocimiento social en el trabajo de campo. Buenos Aires; Barcelona; Ciudad de México: Paidós.

Kent, Michael, Vivette García-Deister, Carlos López-Beltrán, Ricardo Ventura Santos, Ernesto Schwartz-Marín y Peter Wade. 2015. "Building the Genomic Nation: 'Homo Brasilis' and the 'Genoma Mexicano' in Comparative Cultural Perspective”. Social Studies of Science 45 (6): 839-861. https://doi.org/10.1177/0306312715611262

Kent, Michael y Ricardo Ventura-Santos. 2012. “'Os charruas vivem’ nos gaúchos: a vida social de uma pesquisa de 'resgate' genético de uma etnia indígena extinta no Sul do Brasil”. Horizontes Antropológicos 18 (37): 341-372. https://doi.org/10.1590/S0104-718320 12000100015

Klapisch Züber, Christine. 1994. “Árbol genealógico y construcción del parentesco en el Renacimiento”. Quaderni Storici 86 (2): 405-41.

—. 2000. Hombre des ancétres. Essai sur l'imaginaire medieval de la párente. París: Fayard.

López-Beltrán, Carlos. 2011. Genes (\&) mestizos. Ciudad de México: Ficticia Editorial.

Mittos, Alexandros, Jeremy Blackburn y Emiliano de Cristofaro. 2018. "23andMe Confirms: I'm Super White. Analyzing Twitter Discourse On Genetic Testing”. https://www. groundai.com/project/23andme-confirms-im-super-white-analyzing-twitter-discourseon-genetic-testing/

Needham, Rodney. 1960. “Descent Systems and Ideal Language”. Philosophy of Science 27 (1): 96-101. https://www.jstor.org/stable/185309?seq=1

Nelson, Alondra. 2012. "Reconciliation Projects: From Kinship to Justice”. En Genetics and the Unsettled Past: The Collision of DNA, Race and History, editado por Keith Wailoo, Alondra Nelson y Catherine Lee, 20-31. New Jersey: Rutgers University Press.

Peirano, Mariza. 1995. A favor da etnografía. Río de Janeiro: Relume Dumará.

Reardon, Jenny. 2005. Race to the Finish: Identity and Governance in an Age of Genomics. Nueva Jersey: Princeton University Press. 
Rivers, William Halse R. (1910) 1975. "El método genealógico de investigación antropológica”. En La antropología como ciencia, editado por José R. Llobera, 85-96. Barcelona: Anagrama.

Roth, Wendy y Katherine Lyon. 2018. "Genetic Ancestry Tests and Race: Who Takes Them, Why, and How Do They Affect Racial Identities?”. En Reconsidering Race: Social Science Perspectives on Racial Categories in the Age of Genomics, editado por Kazuko Suzuki y Diego A. Von Vacano, 133-169. Oxford: Oxford University Press.

Salzano, Francisco y Mónica Sans. 2014. "Interethnic Admixture and the Evolution of Latin American Populations”. Genetics and Molecular Biology 37 (1): 151-170.

Schneider, David. (1964) 1975. “La naturaleza del parentesco”. En Dumont (1964) 1975, 162-165.

Schwartz-Marín, Ernesto y Peter Wade. 2015. "Explaining the Visible and the Invisible: Public Knowledge of Genetics, Ancestry, Physical Appearance and Race in Colombia”. Social Studies of Science 45 (6): 886-906. https://doi.org/10.1177/0306312715621182

Smith, Lindsay. 2015. "Genetics and Social Justice”. En The International Encyclopedia of Social and Behavioral Sciences, editado por J. Wright, 969-974. Ámsterdam: Elsevier.

Stolcke, Verena. 1998. "El sexo de la biotecnología”. En Genes en el laboratorio y en la fábrica, editado por Alicia Durán y Jorge Riechmann, 97-118. Madrid: Trotta.

Ventura Santos, Ricardo, Peter Fry, Simone Monteiro, Marcos Chor Maio, José Carlos Rodrigues, Luciana Bastos-Rodrigues y Sérgio D. J. Pena. 2009. “Color, Race, and Genomic Ancestry in Brazil: Dialogues between Anthropology and Genetics”. Current Anthropology 50 (6): 787-819. https://doi.org/10.1086/644532

Wade, Peter. 2017. Degrees of Mixture, Degrees of Freedom: Genomics, Multiculturalism, and Race in Latin America. Durham: Duke University Press.

Wailoo, Keith. 2012. "Who Am I? Genes and the Problem of Historical Identity". En Genetics and the Unsettled Past: The Collision of DNA, Race and History, editado por Keith Wailoo, Alondra Nelson y Cattherine Lee. New Jersey: Rutgers University Press.

Walker, Alexa, Brian Egan y George Nicholas, eds. 2016. DNA and Indigeneity. British Columbia: Simon Fraser University. 